TI 2012-142/DSF48/IV

Tinbergen Institute Discussion Paper
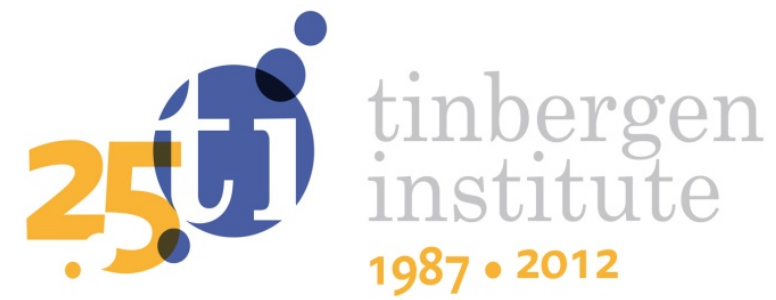

\title{
Credit Protection and Lending Relationships
}

\author{
Stefan Arping
}

Faculty of Economics and Business, University of Amsterdam, and Tinbergen Institute. 
Tinbergen Institute is the graduate school and research institute in economics of Erasmus University Rotterdam, the University of Amsterdam and VU University Amsterdam.

More TI discussion papers can be downloaded at http://www.tinbergen.nl

Tinbergen Institute has two locations:

Tinbergen Institute Amsterdam

Gustav Mahlerplein 117

1082 MS Amsterdam

The Netherlands

Tel.: +31(0)205251600

Tinbergen Institute Rotterdam

Burg. Oudlaan 50

3062 PA Rotterdam

The Netherlands

Tel.: +31(0)10 4088900

Fax: $+31(0) 104089031$

Duisenberg school of finance is a collaboration of the Dutch financial sector and universities, with the ambition to support innovative research and offer top quality academic education in core areas of finance.

DSF research papers can be downloaded at: http://www.dsf.nl/

Duisenberg school of finance

Gustav Mahlerplein 117

1082 MS Amsterdam

The Netherlands

Tel.: +31(0)20 5258579 


\title{
Credit Protection and Lending Relationships*
}

\author{
Stefan Arping ${ }^{\dagger}$
}

This version: November 20, 2012

\begin{abstract}
We examine the impact of CDS protection on lending relationships and efficiency. CDS insulate lenders against losses from forcing borrowers into default and liquidation. This improves the credibility of foreclosure threats, which can have positive implications for borrower incentives and credit availability ex ante. However, lenders may also abuse their enhanced bargaining power vis-⿳亠े⿵-vis borrowers and extract additional surplus in debt renegotiations. If this hold up threat becomes severe, borrowers will be reluctant to agree to debt maturity designs or control right transfers that would have been optimal in the absence of CDS protection. The introduction of CDS markets may then ultimately tighten credit constraints and be detrimental to welfare.

Keywords: Corporate Lending; Financial Innovation; Credit Default Swaps; Credit Derivatives; Credit Risk Transfer; Empty Creditor Problem JEL Classification: G2, G3
\end{abstract}

*This is a heavily revised version of Arping (2004). I thank Daniel Bergstresser, Urs Birchler, Jürg Blum, Arnoud Boot, Stijn Claessens, Erasmo Giambona, Denis Gromb, Michel Habib, Robert Hauswald, Gyongyi Loranth, Ian Marsh, Janet Mitchell, Pierre Monnin, Charlotte Ostergaard, Bruno Parigi, Enrico Perotti, Rafael Repullo, Giancarlo Spagnolo, Javier Suarez, Elu von Thadden, Xavier Vives, Wolf Wagner, Alexandre Ziegler, and seminar participants at the CEPR/BBVA conference "Will Universal Banking Dominate or Disappear?" (Madrid, November 2002), University of Amsterdam, Judge Business School, the ECB/CFS symposium "Capital Markets and Financial Integration in Europe" (Frankfurt, May 2004), the 1st FIRS conference on Banking, Insurance, and Finance (Capri, May 2004), the BIS/CEPR/JFI workshop "Accounting, Transparency, and Bank Stability" (Basel, May 2004), and the 2004 EFA meetings in Maastricht for their comments. The usual disclaimer applies.

†Amsterdam Business School, University of Amsterdam, Finance Group, Roetersstraat 11, 1018 WB Amsterdam, The Netherlands, e-mail: s.r.arping@uva.nl, and Tinbergen Institute 


\section{Introduction}

The credit risk transfer market, and the market for credit default swaps (CDS) in particular, experienced a spectacular rise and fall over the past two decades. Similar to other risk transfer instruments, CDS can facilitate efficient risk sharing and as such expand the extension of credit to the real sector and enhance welfare. However, CDS also can have costs. ${ }^{1}$ Critics point to, among other things, problems arising from the opaqueness of CDS markets, the potential negative effect on banks' monitoring incentive, and lenders' reduced incentive to support their borrowers in difficult times when being protected against losses from default. ${ }^{2}$ While the debate about the costs and benefits of CDS is a long-standing one, it recently became more intense in the wake of the ongoing financial crisis.

Against this background, the aim of the present paper is to analyze the impact of CDS protection on lending relationships and credit market efficiency. We do so in the context of a simple model where loan performance is subject to borrower moral hazard. Our starting point is the observation that CDS protection can make lenders tougher in debt renegotiations. By insulating lenders against losses from default, CDS protection improves lenders' threat point payoff from letting renegotiation fail and forcing borrowers into default and liquidation. We argue that lenders' enhanced bargaining power through CDS protection can have positive or negative implications for borrower incentives ex ante. On the one hand, faced with a more credible threat of foreclosure, borrowers may have an incentive to act less opportunistically in an attempt to make it less worthwhile for their lenders to exercise foreclosure threats. On the other hand, lenders could abuse their enhanced bargaining power and extract excessive rents in debt renegotiations. If this hold up threat becomes severe, it could override the aforementioned disciplining effect. The introduction of CDS markets may then ultimately tighten credit constraints and be detrimental to welfare.

In our base model without CDS protection, a penniless owner-manager run firm needs to borrow funds from a lender for a project. The likelihood of project success depends on the borrower's non-contractible effort and the realization of exogenous uncertainty. This

\footnotetext{
${ }^{1}$ See Stulz (2010) for an account of the debate and a nuanced discussion of the costs and benefits of CDS.

${ }^{2}$ See, e.g., Scott-Quinn and Walmsley (1998) and, more recently, Hu and Black (2008) who coined the term "empty creditor" problem to describe situations where protected lenders have limited economic exposure to borrowers while at the same time holding important liquidation and restructuring rights.
} 
exogenous uncertainty is resolved at an interim stage before project maturity. In bad states of the world, it is efficient to close down the project at the interim stage and liquidate assets in place. However, early termination is privately costly for the borrower. Therefore, if the lender did not have the unilateral right to terminate the project he would have to share the liquidation proceeds with the borrower to overcome her aversion against early closure. As the lender would receive less in bad states of the world, he would demand a higher interest rate. This would be inefficient as it would entail an additional distortion of the borrower's incentive to exert effort. Short-term debt financing allows the parties to resolve this problem. With short-term debt, the lender can simply force default at the interim stage by not rolling over debt, which in turn entitles him to seize project assets.

Suppose now that the lender has the possibility to purchase a CDS vehicle that would entitle him to receive a payout in the event of default and liquidation. What happens at the interim stage? In bad states of the world, the lender will force default and liquidation, as above. He will also reap the protection payout. In exchange, he pays the protection seller a fair premium upfront. So in bad states of the world nothing much changes. The key observation is that CDS protection may change the terms of trade in good states of the world where continuation is efficient. As CDS protection rewards the lender for forcing default, the lender will be less inclined to let the borrower continue even if doing so would be efficient. Knowing this - and anticipating the lender's CDS trade - the borrower may be inclined to work harder in an attempt to make it less worthwhile for the lender to exercise the termination threat. In other words, CDS protection can have a desirable commitment effect on borrower incentives. In the absence of CDS protection, the lender will be reluctant to terminate the borrower's project following opportunistic behavior as part of his investment outlay will be sunk at the interim stage. CDS protection resolves this credibility problem by effectively rewarding the lender for exercising the termination threat.

However, CDS protection also has a cost: it may enable the lender to extract additional surplus even if the borrower sticks to her side of the bargain and exerts efficient effort. If this ex post hold up threat becomes sufficiently severe the borrower's incentive to exert effort will be severely stifled. This, in turn, will make the lender unwilling to finance the project with short-term debt in the first place. The parties will have to resort to "covenant-lite" long-term debt under which the lender is not entitled to force pre--mature liquidation. Yet, 
covenant-lite long-term debt is inefficient as in bad states of the world the lender will have to share the liquidation proceeds with the borrower to overcome her aversion against early project closure. Due to this inefficiency, long-term debt financing may not be feasible either. As a result, financial innovation - the introduction of a "CDS technology" - may, in extreme cases, lead to a breakdown of the credit market.

The excessive rent extraction problem of credit protection would not arise if the lender could credibly commit to abstain from taking more than some "desired" level of protection. One can think of several circumstances where such a commitment could be feasible. First, CDS protection might be contractible between lenders and borrowers. In practice, however, this is unlikely to be the case due to CDS market opaqueness and limits to complete contracting. Second, lenders could be required to disclose CDS trades. As we will show in Section 4, mere observability of CDS trades to borrowers may be sufficient to achieve commitment. Third, debt renegotiation may not be feasible due to bargaining imperfections. In the presence of ex ante uncertainty about the feasibility of renegotiation, taking "excessive" protection may be suboptimal for the lender as it may entail a prohibitively high premium. This is because protection sellers are willing to advance protection against relatively low premia only if they can be assured that termination threats are ultimately not exercised in states of the world where continuation is efficient. Yet, if the lender's level of protection is excessive and debt renegotiation where the lender could sort out matters with the borrower turns out to be infeasible, the project will be terminated not only in bad states of the world but also in good states. This will result in a very high premium, which in turn deters the lender from taking excessive protection in the first place.

Our analysis yields several empirical implications. In our model, firms with relatively low levels of asset tangibility and firms where debt renegotiation is more cumbersome are more prone to benefit from CDS protection. To the extent that debt renegotiation is more difficult at large firms - i.e., firms that often have relatively complex and dispersed financial structures - this may suggest that the benefits of CDS protection could be confined to relatively large firms, as documented by Hirtle (2009). The analysis also has implications for loan contract design. Borrowers that would suffer from the excessive rent extraction problem of CDS protection should be reluctant to agree to debt maturity designs and control right transfers that would enable their lenders to impose foreclosure threats in the first 
place. Following the introduction of CDS markets, one would thus expect a lengthening a debt maturities across the cross-section of borrowers. This appears to be consistent with empirical evidence reported in Saretto and Tookes (2012).

This paper complements a growing literature on the corporate finance implications of credit derivatives and credit risk transfer at large. ${ }^{3}$ Pennacchi (1988), Carlstrom and Samolyk (1995), Gorton and Pennacchi (1995), Morrison (2005), Marsh and Wagner (2006), and Parlour and Plantin (2008), among others, analyze credit risk transfer in models where lenders are subject to institutional risk aversion due to capital constraints or financial distress concerns. In these models, risk transfer can facilitate efficient risk sharing and diversification. Part or all of these benefits may accrue to the real sector in terms of improved access to credit and lowered funding costs. The downside of risk transfer is that it may undermine lenders' incentive to perform monitoring or other value-enhancing activities. A key policy insight of this literature is that efficient risk transfer requires lenders retaining sufficient economic exposure to their borrowers ("skin in the game"). One contribution of our paper relative to this literature is to show that risk transfer can have benefits even when the traditional motive for risk transfer due to lender risk aversion plays no role. Duffee and Zhou (2001) study risk transfer vehicles in an adverse selection context. In their model, CDS provide more flexibility than loan sales in terms of minimizing adverse selection costs of risk transfers. Chiesa (2008) develops a model where banks' monitoring effort is particularly worthwhile in economic downturns, as a result of which debt financing of banks is suboptimal in her setting. She shows that securitization can implement welfare optimal bank capital structures, provided banks retain first-loss positions and regulators put stringent capital requirements. Allen and Carletti (2006) analyze risk transfer in a model with potential for inter-sector contagion. Depending on the nature of liquidity shocks, risk transfer can be welfare-enhancing or detrimental to welfare. In the latter case, risk transfer may increase the risk of crisis and lead to contagion.

The disciplining effect of credit protection proposed in this paper is also central to a number of more recent papers. Goderis and Wagner (2005) embed CDS into a model of sovereign debt default and restructuring. Credit protection lowers ex ante debtor moral

\footnotetext{
${ }^{3}$ There also is an emerging general equilibrium literature studying the impact of CDS on asset prices. See, among others, Geanakoplos (2009), Che and Sethi (2010), and Fostel and Geanakoplos (2011).
} 
hazard, but it may also be detrimental to crisis solution by making restructuring more difficult. Sambalaibat (2011) too argues that CDS can alleviate debtor moral hazard, but he also shows that the existence of "naked buyers" in the protection market may impede this disciplining effect, in particular when the protection market is imperfectly competitive. Bolton and Oehmke (2011) show that CDS can help to reduce the incidence of strategic default. However, lenders will "overinsure" in equilibrium, giving rise to an inefficiently high incidence of bankruptcy. Our model instead emphasizes the hold up threat introduced by CDS protection and its effect on borrower incentives and credit availability ex ante. Campello and Matta (2012) develop a model examining CDS contracts when restructuring is costly and investment is subject to moral hazard. Their analysis shows how the state of the economy influences the demand for CDS and how CDS contracts affect the supply of credit over the business cycle. Their analysis also shows that banning CDS "overinsurance" can be detrimental to welfare. Matta (2011) examines optimal financing policies in the presence of CDS when lenders have different exposures to borrowers' risk. In his model, credit protection benefits safe borrowers and harms risky ones.

Our paper also relates to Rajan's (1992) seminal work on debt maturity design and hold up threats in lending. As in our model, short-term debt can facilitate efficient liquidation and improve borrower incentives. The cost of short-term debt is that gives rise to a hold up problem in that it enables the lender to extract additional surplus in renegotiation. This differs from our setting where short-term debt in itself does not give rise to a hold up problem. The reason is that in our model (and in contrast to Rajan 1992) the lender has the option to roll over short-term debt. As a result, hold up threats lack credibility in the absence of CDS protection. CDS protection can make such threats credible if and when CDS trades are non-contractible between lenders and borrowers.

The paper is organized as follows. The next section outlines the basic model and characterizes the credit market equilibrium in the absence of credit protection. Section 3 introduces credit protection and analyzes its effects. Section 4 provides a discussion of policy implications. Empirical implications are discussed in Section 5, and Section 6 concludes. 


\section{Basic Model and Analysis}

We consider an economy with three classes of agents: a penniless owner-manager run firm (henceforth, "borrower"), lenders, and credit protection sellers. The borrower has an idea for a project for which she requires funding from a lender. The lender can purchase credit protection (in form of a CDS) from a credit protection seller. Both credit and credit protection markets are perfectly competitive. All agents are risk-neutral, ${ }^{4}$ there is no discounting, and the borrower is protected by limited liability.

\subsection{Setup}

The model has three dates, $t=0,1,2$. At date 0 , the project can be undertaken at cost $I>0$. Once the project is underway, the borrower can exert non-contractible effort $e \in[0,1]$ at private $\operatorname{cost} \psi(e)=\beta e^{2}$, where $\beta>0$ is sufficiently large to ensure interior solutions. ${ }^{5}$ Effort will improve the probability of project success, as specified below. At date 1, exogenous uncertainty about the prospects of the firm realizes. There are two states, "good" and "bad". Let $\theta \in(0,1)$ denote the probability of the good state. The state is non-contractible but observable to both the lender and the borrower. After the realization of the state, the project may be terminated and assets liquidated. The liquidation value of project assets is $L \in(0, I)$ at date 1 and zero at date 2 . The borrower incurs a small private cost $B \in(0, L)$ if the project is terminated (e.g., because of loss of reputation). At date 2 , if the project is continued, final and verifiable cash flows realize. In the good state (and absent default at date 1 , see below), cash flows are $\Pi>0$ with probability $e$ and zero with probability $1-e$. In the bad state, cash flows are zero with probability one. We assume

$$
\max _{e \in[0,1]}\{\theta e \Pi+(1-\theta)(L-B)-\psi(e)\}>I
$$

In other words, conditional on the borrower exerting efficient effort and the project being continued in the good state and terminated in the bad state, the net present value of the

\footnotetext{
${ }^{4}$ We also assume that investors do not face financial distress costs or regulatory capital constraints. In other words, we abstract from the traditional institutional "risk aversion" based motive for credit risk transfer. See Arping (2004) for an extension of the model that incorporates lender "risk aversion".

${ }^{5}$ Effort should be interpreted broadly. It may refer to R\&D, cost-cutting, marketing, and other forms of managerial effort, making discretionary investments that enhance firm value but are privately costly, and more generally abstaining from inefficient actions that, while being privately beneficial, do harm lenders.
} 


Loan contract signed.
Project undertaken at cost $I$.
Borrower exerts non-contractible effort $e$.

Borrower exerts non-contractible effort $e$.
State realizes:

- "Good" with probability $\theta$

- "Bad" with probability 1- $\theta$

State is non-contractible but observable to lender and borrower. Lender also observes effort.

Parties may renegotiate loan contractsee Section 2.2.
If continued at date 1 , project generates final and verifiable cash flows:

- In the good state (and absent default at date 1 ), cash flows are $\Pi>0$ with probability $e$ and zero with probability $1-e$.

- In the bad state, cash flows are zero with probability one.

Assets are worthless.

Project is either continued or terminated. If terminated, project assets are liquidated for value $L<I$ and borrower incurs private cost $B<L$.

Figure 1: Sequence of Events

project is positive. For later reference, let $e^{F B}$ denote the efficient effort level.

While the borrower's managerial decision-making ("effort") is non-contractible, it is assumed to be observable to the borrower's lender (e.g., by virtue of his close relationship with the borrower, ongoing due diligence, etc.). Non-contractibility of effort, in conjunction with limited liability, gives rise to a standard moral hazard problem. Observability of effort, as we shall see below, has the advantage that the lender can potentially improve the borrower's incentive to exert effort by threatening to terminate the project should she underprovide effort. Figure 1 illustrates the sequence of events.

\subsection{Credit Market Equilibrium in the Absence of CDS}

As a useful point of reference, let us first characterize the credit market equilibrium in the absence of credit protection. Credit protection will be introduced in Section 3 .

We consider two types of financial contracts: "short-term debt" and "long-term debt". The key difference between these contracts is that short-term debt will provide the lender with the option to terminate the project at the interim stage, whereas with long-term debt the lender will not have this option. Let us consider first the case of short-term debt. Short-term debt specifies a repayment $R_{s}$ due at date 1 . This payment can be rolled over 
to date 2 at the discretion of the lender. We assume that if debt is not rolled over (possibly after debt restructuring, see below) default will be induced at date $1 .{ }^{6}$ Default entitles the lender to seize project assets. We also assume that default is costly in that it would disrupt the borrower's business (for instance, because customers would run away; see, e.g., Opler and Titman 1994). For simplicity, default wipes out the business: conditional on default continuation cash flows are zero. ${ }^{7}$

Thus, with short-term debt, the borrower faces the possibility of "financial distress" at date 1: if debt were not rolled over, she would have to default and project assets would be liquidated. To avoid default and liquidation, the parties may want to renegotiate the terms of the loan contract. This will become relevant in the good state when the lender prefers to not roll over debt under the original terms but project termination is inefficient. ${ }^{8}$ In this case, it is mutually beneficial for the parties to renegotiate the loan contract and agree on a new interest rate that makes the lender willing to continue. In practice, debt renegotiation may be subject to delays, transaction costs, or other hurdles, all of which may render efficient bargaining infeasible. To capture such bargaining imperfections, we assume that there is uncertainty with respect to the feasibility of renegotiation. From an ex ante perspective, renegotiation is feasible with probability $\lambda \in[0,1]$. The overall renegotiation game is then modeled as follows. At date 1, the parties learn whether renegotiation is feasible or not. If renegotiation is not feasible, the original loan contract remains in place. If renegotiation is feasible, the borrower has the opportunity to make a take-it-or leave-it renegotiation offer to the lender. ${ }^{9}$ If the lender accepts, the original contract is replaced by the borrower's offer. Otherwise, the original contract remains in place.

Let us begin the analysis with the following observation:

\footnotetext{
${ }^{6}$ In theory, the borrower may seek to borrow fresh funds from another lender and pay the initial lender out of these funds. However, given that she and the initial lender have an informational advantage vis-à-vis outside lenders, outside lenders will be reluctant to advance such funds (cf., Rajan 1992).

${ }^{7}$ This implies that project termination is efficient following default, which simplifies the analysis.

${ }^{8}$ In the bad state, project termination is efficient. Hence, there is no scope for renegotiation. Also, in the good state, if the lender prefers to continue (i.e., roll over debt) under the original terms, then there is no scope for renegotiation either. This is because if in the good state the lender prefers to continue, then continuation is efficient. Thus, renegotiation of the interest rate cannot be mutually beneficial.

${ }^{9}$ In other words, the borrower has the full bargaining power in renegotiation. This is inessential: none of the key results would change if the lender made a take-it-or-leave-it renegotiation offer to the borrower.
} 
Observation 1 Suppose the lender can commit to terminate the project (i.e., not roll over short-term debt) in the good state if and only if the borrower exerts less than efficient effort, $e<e^{F B}$. Then, in equilibrium, the project is undertaken and continued (terminated) in the good (bad) state, the borrower exerts efficient effort, and the lender just breaks even.

To prove this, let the lender advance funds $I$ against a short-term claim $R_{s}=(I-$ $(1-\theta) L) /\left(\theta e^{F B}\right)$. Given this claim, the lender will just break even on his investment if the borrower exerts efficient effort and the project is continued (terminated) in the good (bad) state. In the good state, the lender rolls over debt if and only if $e \geq e^{F B}$. In the bad state, he does not roll over debt and the project is terminated. Therefore, the borrower's payoff from exerting effort $e$ is

$$
U(e)= \begin{cases}\theta e\left(\Pi-R_{s}\right)-(1-\theta) B-\psi(e) & \text { for } e \geq e^{F B} \\ -B-\psi(e) & \text { for } e<e^{F B}\end{cases}
$$

This is maximized at $e^{F B}$. Thus, the first best is achieved.

Observation 1 shows how the threat of termination implicit in short-term debt may reduce the risk of moral hazard. The problem at hand is that the threat of termination lacks credibility. While the lender certainly does not roll over debt in the good state following large deviations from efficient effort, he strictly prefers to continue following small deviations from efficient effort. Formally, since $I>L$, there is some $\epsilon>0$ such that for any $e \geq e^{F B}-\epsilon$ the lender strictly prefers to continue the project in the good state,

$$
e R_{s}=e \times \frac{I-(1-\theta) L}{\theta e^{F B}}>L
$$

Consequently, efficient effort is not incentive-compatible: the borrower knows that small deviations from efficient effort will not be penalized. As part of the benefits from working hard will accrue to the lender, the borrower will exert less than efficient effort.

One may then wonder whether implementing efficient effort $e^{F B}$ is not too ambitious, and whether the threat of termination may be credible for some other (still relatively high) candidate equilibrium effort level $e^{*}<e^{F B}$. The next observation provides the answer:

Observation 2 In the absence of $C D S$, the threat of termination is irrelevant for incentives.

The key problem is that the lender cannot recoup his investment outlay by terminating the project: the asset liquidation value is too small. As a result, the lender necessarily 
strictly prefers to continue the project in equilibrium (in the good state), and consequently he still prefers to continue following small out-of-equilibrium deviations from $e^{*}$. The threat of termination is then irrelevant for incentives: the borrower's payoff from exerting effort $e \geq e^{*}-\epsilon$, where $\epsilon>0$, is

$$
U(e)=\theta e\left(\Pi-R_{s}\right)-(1-\theta) B-\psi(e)
$$

Therefore, incentive-compatibility requires

$$
U^{\prime}\left(e^{*}\right)=\theta\left(\Pi-R_{s}\right)-\psi^{\prime}\left(e^{*}\right)=0
$$

This is merely the incentive constraint in the absence of termination threats. Equilibrium effort is then given by the largest solution of the incentive constraint (2), with $R_{s}$ such that the lender just breaks even (i.e., $\left.R_{s}=(I-(1-\theta) L) /\left(\theta e^{*}\right)\right)$.

Let us now turn to the case of long-term debt. Long-term debt specifies a repayment $R_{l}$ due at date 2 and it is "covenant-lite" in that the lender does not have the implicit or explicit right to terminate the project at date $1 .{ }^{10}$ Thus, with covenant-lite long-term debt the lender cannot simply force liquidation of the project: liquidation requires the borrower's consent. As liquidation is privately costly for the borrower, she will agree to terminate the project in the bad state if and only if she is compensated for the reputation cost. To implement this, it suffices to put a sharing rule in the contract whereby the borrower receives $B$ in the event of liquidation and the lender $L-B$. Under this sharing rule, the borrower just has the right incentive to agree to terminate the project in the bad state. Of course, the problem with long-term debt is that it will be more "expensive" than short-term debt: as the lender receives less in the bad state, he must be paid more in the event of project success. This gives rise to an additional incentive distortion relative to short-term debt. Consequently, covenant-lite long-term debt is strictly suboptimal. ${ }^{11}$

Proposition 1 In the absence of CDS, short-term debt strictly dominates long-term debt. If the project is undertaken, the borrower exerts effort

$$
e_{s}^{*}=\frac{\theta \Pi+\sqrt{(\theta \Pi)^{2}-8 \beta(I-(1-\theta) L)}}{4 \beta}<e^{F B}
$$

\footnotetext{
${ }^{10}$ E.g., the loan contract does not contain a covenant that would give the lender discretion to demand early repayment (a loose "material adverse change" clause). This would be equivalent to short-term debt.

${ }^{11}$ As we shall see below, this may no longer be the case once we introduce a market for credit protection.
} 
The borrower may be credit rationed: there is a debt capacity threshold $I_{s}<\theta e^{F B} \Pi+(1-$ $\theta)(L-B)-\psi\left(e^{F B}\right)$ such that the project will be undertaken if and only if $I \leq I_{s}$.

Proof: See the Appendix.

For later reference, notice that if the project were financed with long-term debt the borrower's effort level and debt capacity would be given by

$$
e_{l}^{*}=\frac{\theta \Pi+\sqrt{(\theta \Pi)^{2}-8 \beta(I-(1-\theta)(L-B))}}{4 \beta}<e_{s}^{*}
$$

and some $I_{l}<I_{s}$, respectively. The difference stems from the fact that with long-term debt the lender's payoff in the bad state is $L-B$, rather than $L$. As the lender receives less in the bad state, he must receive more in the good state. This entails an additional effort distortion.

\section{Credit Protection}

We now introduce a market for credit protection. As we shall see below, the reason why credit protection matters in our setting is that it alters the lender's outside option payoff from exercising the termination threat under short-term debt financing. By contrast, credit protection is irrelevant under long-term debt financing under which the lender is not entitled to intervene early and force pre-mature default. ${ }^{12}$ Thus, when analyzing the lender's incentive to purchase credit protection and the effect of such a purchase on lending outcomes, it suffices to consider the case of short-term debt financing. ${ }^{13}$

Once having provided funding, the lender can purchase a CDS from a credit protection seller. The protection seller is at arm's length and does not participate in workouts between the lender and the borrower. A CDS specifies a premium $P$ to be paid upfront to the seller and a contingent payment $C$ from the seller to the buyer in the event of a pre-

\footnotetext{
${ }^{12}$ This follows from our simplifying assumption that the lender is not subject to risk aversion due to, e.g., financial distress concerns. As a result, the standard hedging motive plays no role here.

${ }^{13}$ This is not to say that long-term debt is irrelevant in the presence of a market for credit protection. As we shall see below, it could be that short-term debt financing is no longer feasible once the lender has the possibility to purchase protection. If so the parties will have to resort to long-term debt financing.
} 
specified "credit event". ${ }^{14}$ In our setting, the credit event constitutes default at date $1 .{ }^{15}$ By contrast, private workouts - being private - do not constitute credit events.

Notice that as default wipes out the borrower's business there is no point in continuing the project following default. The lender and the protection seller will agree that the project should be liquidated, and the project will be liquidated. We assume without loss of generality that the liquidation proceeds accrue to the lender. ${ }^{16}$ Therefore, the lender's default-contingent payoff is $L+C$ and the protection seller's payoff is $-C$.

\subsection{Contractible Credit Protection: First Best}

Let us consider in a first step the case where credit protection is contractible between the lender and the borrower. By this we mean that the lender can contractually commit to a specific transaction in the CDS market and that such a commitment is enforceable. The loan contract will then specify that the lender must engage in a particular CDS transaction, and no other transaction, and enforceability will ensure that the lender will adhere to this commitment. While the case of contractible credit protection appears to be at odds with the nature of the CDS market (see below), it will serve as a useful benchmark case.

Proposition 2 Suppose credit protection is contractible between the lender and the borrower. Then, in equilibrium, the project is undertaken and continued (terminated) in the good (bad) state, the borrower exerts efficient effort, and investors just break even.

Proof: See the Appendix.

The proposition shows that the introduction of a market for credit protection market can improve efficiency in the market for credit. This may be surprising at first sight since the traditional institutional risk aversion based motive for risk sharing plays no role in our setting. In our setting, credit protection is beneficial due to its commitment effect on borrower incentives. Credit protection makes it less costly for the lender to force the

\footnotetext{
${ }^{14}$ We discuss in Section 4.1 how the CDS considered here can be implemented with plain-vanilla CDS.

${ }^{15} \mathrm{In}$ an earlier version of the paper (Arping 2004), we also allowed for "long-term" protection, i.e., a payout conditional on default at date 2 . There we showed that long-term protection is suboptimal.

${ }^{16}$ Equivalently, one could consider a protection payment $C^{\prime}=L+C$ and assume that the liquidation proceeds accrue to the protection seller. This would yield the same default-contingent payoffs.
} 
borrower into default and liquidation. In essence, credit protection enhances the value of collateral for the lender. This improves the credibility of termination threats, which in turn has positive implications for borrower incentives and credit availability ex ante.

To see this more formally, let the lender advance funds $I$ against a claim $R_{s}=(I-(1-$ $\theta) L) /\left(\theta e^{F B}\right)$. Furthermore, let the lender purchase credit protection $C=(I-L) / \theta$ against a premium $P=(1-\theta) C$. Consider the lender's incentive to roll over debt. In the bad state, the lender does not roll over debt and the project is terminated. In the good state, the lender is willing to continue under the existing contract if and only if

$$
e R_{s}=e \times \frac{I-(1-\theta) L}{\theta e^{F B}} \geq L+C=\frac{I-(1-\theta) L}{\theta}
$$

By inspection, this inequality reduces to $e \geq e^{F B}$ : the lender is willing to continue if and only if the borrower exerts at least efficient effort. Faced with this threat, the borrower has no incentive to shirk: if she did she would either face outright project termination or she would have to fully compensate the lender for the cost of shirking. In equilibrium, the borrower will exert efficient effort, and hence the threat of termination will not be exercised in the good state. ${ }^{17}$ The lender will induce default and reap the protection payout $C$ only in the bad state. In exchange, the lenders pays a fair premium $P=(1-\theta) C$ upfront. Both the lender and the protection seller just break even in equilibrium. ${ }^{18}$

\footnotetext{
${ }^{17}$ In fact, the threat of termination may not be exercised even off-the-equilibrium path. Renegotiation between the lender and borrower, if feasible, will ensure that following small deviations from efficient effort debt will ultimately be rolled over in the good state. Furthermore, given that the protection seller is at arm's length, it is not him but the borrower who will have to reward the lender for continuation.

${ }^{18} \mathrm{An}$ alternative mechanism to make the termination threat credible would be to finance the project with more than one investor (see, among others, Berglöf and von Thadden 1994, Dewatripont and Tirole 1994, Bolton and Scharfstein 1996, and, closest related to our setting, Repullo and Suarez 1998). The borrower would raise $L$ from our lender against a short-term debt claim that is secured by project assets. The remainder of the investment outlay would be financed by issuing long-term debt to arm's length investors. In equilibrium, the secured lender would be indifferent between termination and continuation in the good state, and hence the threat of termination would be credible. However, as shown by Repullo and Suarez (1998), the first best is in general not achievable with this co-financing mechanism. This is because longterm investors' claim entails an incentive distortion as it dilutes the joint surplus of the secured lender and the borrower. Similarly, in our setting, "long-term" protection, i.e., a payout conditional on default at date 2 , would entail an incentive distortion as it effectively would reward the lender and the borrower for project failure. Thus, while the optimal protection vehicle provides full protection at date 1, it does not protect
} 


\subsection{Non-Contractible Credit Protection: Hold Up}

In practice, CDS are traded over-the-counter and lenders' transactions in the protection market may not be readily observable to borrowers. More importantly, specifying such transactions ex ante in loan contracts may not be feasible, e.g., due to limits to complete contracting. That is, credit protection is unlikely to be contractible between lenders and borrowers. To account for this, we will drop the assumption that credit protection is contractible in what follows. We consider the following setup. Once having provided funding, the lender can purchase a CDS. As above, a CDS specifies some default-contingent-and possibly very large - payment $C$ to the lender and an upfront premium $P$ to the protection seller. This transaction is not observed by the borrower when exerting effort (but it may be disclosed to her when it comes to debt renegotiation at date 1). It is furthermore non-contractible between the lender and the borrower. At date 1, the state realizes and the lender observes effort. Default may or may not be induced and the parties may or may not renegotiate in a private workout.

\subsubsection{Perfect Renegotiation}

Let us momentarily abstract from limits to renegotiation and assume renegotiation is feasible always (i.e., $\lambda=1$ ). How much credit protection will the lender purchase? Consider a candidate equilibrium in which the project is financed with short-term debt $R_{s}<\Pi$ and the borrower exerts effort $e^{*}$. Clearly, it must be the case that $e^{*}$ is such that in the absence of credit protection termination in the good state is inefficient for the lender and the borrower; otherwise, the project would not have been undertaken in the first place. We then need to consider two cases: either the lender purchases protection such that given effort $e^{*}$ he is willing to continue the project in the good state under the existing loan contract, i.e., $C \leq e^{*} R_{s}-L$, or the lender purchases "excessive" protection $C>e^{*} R_{s}-L$. In the former case, the lender's overall expected payoff is

$$
\theta e^{*} R_{s}+(1-\theta)(L+C)-\underbrace{(1-\theta) C}_{=P}=\theta e^{*} R_{s}+(1-\theta) L
$$

the lender against losses from default at date 2. In this context, the advantage of credit protection relative to co-financing stems from its greater flexibility in terms of optimizing the lender's exposure to credit risk over the course of the lending relationship (see also Duffee and Zhou 2001). 
where $P$ denotes the premium paid upfront. Notice that the expected protection payout is just offset by the premium. In the latter case, the lender is no longer willing to continue in the good state under the existing contract, given effort $e^{*}$. However, as long as $C$ is not too large either, project termination in the good state is inefficient for the lender and the borrower, and hence renegotiation is triggered. In renegotiation, the borrower offers the lender a new claim $R_{s}^{\prime}>R_{s}$ such that the lender is just willing to continue,

$$
e^{*} R_{s}^{\prime}=L+C
$$

Thus the lender's payoff from purchasing excessive protection is

$$
\theta \underbrace{(L+C)}_{=e^{*} R_{s}^{\prime}}+(1-\theta)(L+C)-\underbrace{(1-\theta) C}_{=P}=L+\theta C
$$

which is increasing in $C$. The key difference with respect to the preceding case is that now the lender's payoff in the good state is determined by his outside option payoff from inducing default, i.e., $L+C$. Therefore, the larger is $C$, the more the borrower will have to pay to the lender to induce him to continue in the good state.

Will the lender purchase a very large amount of protection, possibly, an infinite amount? Clearly not, for if he did termination would become efficient for the lender and the borrower, and hence the project would be terminated in both states. The premium would be set accordingly and the lender would end up with a payoff of $L$. The lender will therefore maximize $C$ subject to the constraint that the project will be continued in the good state, i.e., the workout will not fail. The workout will not fail as long as (i) continuation in the good state is efficient for the lender and the borrower, $e^{*} \Pi \geq L+C-B$, and (ii) the borrower's cash constraint is not violated, $R_{s}^{\prime}=(L+C) / e^{*} \leq \Pi$. The first constraint is clearly implied by the second, and hence the optimal level of protection is

$$
C=e^{*} \Pi-L
$$

This allows the lender to extract a payment $R_{s}^{\prime}=\Pi$ and to obtain an expected payoff of

$$
\theta e^{*} \Pi+(1-\theta) L
$$

which exceeds (3). Ultimately, therefore, the lender will extract the entire project surplus from the borrower. This leads to the following result: 
Proposition 3 Suppose there are no obstacles to renegotiation (i.e., $\lambda=1$ ) and the borrower's reputation cost $B$ is sufficiently small. Then, the introduction of a market for credit protection will harm efficiency in the market for credit. In particular, short-term debt financing is no longer feasible. The parties will have to resort to inefficient covenant-lite long-term debt financing. As long-term debt financing may not be feasible either, the introduction of a credit protection market may lead to a breakdown of the credit market.

Proof: See the Appendix.

Under short-term debt financing, the lender would purchase excessive protection in an attempt to hold up the borrower and extract an additional payment in the workout. Ultimately, the lender would extract the entire project surplus. The borrower would respond by exerting zero effort (as long as $B$ is small, see below). This in turn makes the lender unwilling to provide short-term debt financing in the first place. The parties will have to resort to covenant-lite long-term debt financing under which the lender does not have the option to induce default. However, as seen above, there are cases where, in the absence of credit protection, short-term debt financing is feasible while long-term debt financing is not. As a result, borrowers that would have obtained funding in the absence of credit protection may find themselves credit rationed once credit protection is introduced.

To see why the reputation cost $B$ must be small for Proposition 3 to hold, let us show that if $B$ is sufficiently large the first best can still be achieved. From the preceding analysis we know that the lender's best response to the borrower exerting efficient effort is to purchase protection $C=e^{F B} \Pi-L$. Consider then the borrower's incentive to exert effort, given $C=e^{F B} \Pi-L$. The borrower knows that if she exerts effort $e \geq e^{F B}$ the project will be continued in the good state against her committing to pay $R_{s}^{\prime}=(L+C) / e=e^{F B} \Pi / e$. In the bad state, the project will be terminated. The borrower's expected payoff from exerting effort $e \geq e^{F B}$ is

$$
U(e)_{e \geq e^{F B}}=\theta e\left(\Pi-\left(e^{F B} \Pi\right) / e\right)-(1-\theta) B-\psi(e)
$$

This is maximized at $e^{F B}$. Conversely, if the borrower exerts effort $e<e^{F B}$ the project will be terminated in both states. Therefore, if the borrower found it optimal to exert effort $e<e^{F B}$, she would exert zero effort and derive a payoff of $-B$. The overall incentive 
constraint boils down to $U\left(e^{F B}\right)_{e \geq e^{F B}}=-(1-\theta) B-\psi\left(e^{F B}\right) \geq-B$, or

$$
B \geq \psi\left(e^{F B}\right) / \theta
$$

As long as (4) holds the first best can still be achieved. One optimal contract in this case is such that the entire project cash flows are pledged to the lender, $R_{s}=\Pi$. In exchange, the lender transfers more upfront, namely, $T=\theta e^{F B} \Pi+(1-\theta) L>I$, out of which $I$ is used for the project (the remainder is consumed by the borrower or paid out as a dividend). Given this contract, purchasing protection $C=e^{F B} \Pi-L$ is a weakly dominant strategy for the lender. The threat of incurring the reputation $\operatorname{cost} B$ in the event of project termination ensures that the borrower has an incentive to exert efficient effort, even though cash flows accrue fully to the lender. Above, we exclude this possibility by assuming that $B$ is "small". More specifically, let us assume

$$
B<\psi\left(e^{\min }\right) / \theta
$$

where $e^{\text {min }}$ is the critical effort level where project NPV is just zero (see the Appendix). Under this assumption, short-term debt financing is not feasible when there are no obstacles to renegotiation.

\subsubsection{Imperfect Renegotiation}

The preceding analysis relies on renegotiation being "perfect". We now turn to the more realistic case where there are limits to renegotiation. Our goal is to show that as long as the likelihood of a renegotiation breakdown is sufficiently large, credit protection will again have positive implications for credit market efficiency.

From above, we know that the "ideal" level of protection is such that the lender is just willing to continue the project in the good state, given efficient effort, i.e.,

$$
e^{F B} R_{s}=L+C
$$

where $R_{s}<\Pi$ is the lender's debt claim. At this level of protection, the lender is fully protected against deviations from efficient effort $e^{F B}$. Of course, the problem is that protection is non-contractible, and hence the parties have to ensure that the lender does not deviate and purchase more than the desired level of protection. ${ }^{19}$ From the preceding anal-

\footnotetext{
${ }^{19}$ The lender will have no incentive to "underinsure". As above, purchasing little (or no) protection is weakly dominated by purchasing the desired level of protection.
} 
ysis, we know that the lender will never purchase protection $C>e^{F B} \Pi-L$. Suppose the lender purchases protection $C \in\left(e^{F B} R_{s}-L, e^{F B} \Pi-L\right]$. At date 1 , a workout is feasible with probability $\lambda$. If the workout is feasible the project will be continued in the good state against the borrower committing to pay $R_{s}^{\prime}=(L+C) / e^{F B}$. Conversely, if the workout is not feasible the project will be liquidated. Thus the lender's expected payoff from purchasing excessive protection is

$$
L+C-\underbrace{(\theta(1-\lambda)+(1-\theta)) C}_{=P}=L+\lambda \theta C
$$

where, as above, $P$ denotes the premium paid to the protection seller. To see the difference with respect to the previous analysis, notice that now the workout in the good state is feasible only with probability $\lambda$. Therefore, if the lender purchases excessive protection, default and liquidation will be induced not only in the bad state but potentially also in the good state. The protection seller responds by charging a higher premium. This in turn makes it less profitable for the lender to purchase excessive protection.

At any rate, the lender's payoff from purchasing excessive protection is increasing in $C$ (as long as $\lambda>0$ ), and hence he will optimally purchase protection $C=e^{F B} \Pi-L$ should he have an incentive to purchase excessive protection. Thus lender has no incentive to purchase excessive protection if and only if

$$
\underbrace{\theta e^{F B} R_{s}+(1-\theta) L}_{\text {payoff } C=e^{F B} R_{s}-L} \geq \underbrace{L+\lambda \theta\left(e^{F B} \Pi-L\right)}_{\text {payoff } C=e^{F B} \Pi-L}
$$

This reduces to the following expression

$$
e^{F B} R_{s} \geq \lambda e^{F B} \Pi+(1-\lambda) L
$$

which we will refer to as the "no-hold-up" constraint. The LHS is the lender's payoff in the good state when he sticks to $C=e^{F B} R_{s}-L$ and the RHS is his payoff in the good state from purchasing excessive protection. Intuitively, purchasing excessive protection is risky for the lender: if the workout is feasible he will grab the entire project surplus, but if it is not he will fall back to the asset liquidation value. Thus, a decrease in the probability of a workout being feasible, $\lambda$, or a decrease in the asset liquidation value $L$ tend to relax the no-hold-up constraint. An increase in leverage (i.e., $R_{s}$ ) also relaxes the no-hold-up 
constraint. The intuition is that if the lender is already promised a relatively large payment under the status-quo contract, the extra payment that the lender might be able to extract in a workout will be relatively small. This suggests that the parties may wish to increase leverage in order to relax the no-hold-up constraint, a possibility that we will come back to shortly below. Lastly, notice that the effect of $\Pi$ and the other exogenous variables affecting $e^{F B}$ (i.e., $\theta$ and $\beta$ ) are ambiguous. For example, while a ceteris paribus increase in $\Pi$ tightens the no-hold-up constraint through its effect on the RHS of (5), an increase in $\Pi$ also raises $e^{F B}$ which in turn increases both sides of (5). As a result, the overall effect of $\Pi$ on the no-hold-up constraint is ambiguous.

Suppose now that the lender advances funds $T=I$ against a claim $R_{s}=(I-(1-$ $\theta) L) /\left(\theta e^{F B}\right)$. The desired level of protection is $C=(I-L) / \theta$. From Section 3.1, we know that if the no-hold-up constraint (5) holds, the first best will be achieved. The no-hold-up constraint holds if and only if

$$
\lambda \leq \frac{I-L}{\theta\left(e^{F B} \Pi-L\right)} \equiv \hat{\lambda}^{\min }
$$

Notice that $\hat{\lambda}^{\text {min }} \in(0,1)$ by $I>L$ and (1). There thus is a range of $\lambda$ 's for which the first best can be achieved. For $\lambda>\hat{\lambda}^{\text {min }}$, the first best cannot be implemented with the contract stated above. The parties may then still achieve the first best by raising the lender's claim $R_{s}$, i.e., increasing leverage, in an attempt to relax the no-hold-up constraint. In exchange for the increased claim, the lender transfers an additional amount upfront. ${ }^{20}$ The credible threat of termination ensures that efficient effort is locally incentive-compatible. Overall incentive-compatibility requires that the borrower prefers exerting efficient effort to exerting no effort at all,

$$
\theta e^{F B}\left(\Pi-R_{s}\right)-(1-\theta) B-\psi\left(e^{F B}\right) \geq-B
$$

which can be rewritten as

$$
R_{s} \leq \Pi-\frac{\psi\left(e^{F B}\right)-\theta B}{\theta e^{F B}} \equiv R_{s}^{\max }<\Pi
$$

Substituting for $R_{s}^{\max }$, the no-hold-up constraint (5) reduces to

$$
\lambda \leq 1-\frac{\psi\left(e^{F B}\right)-\theta B}{\theta\left(e^{F B} \Pi-L\right)} \equiv \hat{\lambda}^{\max }
$$

\footnotetext{
${ }^{20}$ As above, this additional amount is consumed by the borrower or paid out as dividend.
} 
Notice that $\hat{\lambda}^{\text {min }}<\hat{\lambda}^{\text {max }}<1$. Thus, for $\lambda \leq \hat{\lambda}^{\text {min }}$ the first best can be achieved with minimum leverage, i.e., the lender just advancing the funds that are necessary to undertake the project. For $\hat{\lambda}^{\text {min }}<\lambda \leq \hat{\lambda}^{\text {max }}$ the first best can still be achieved. However the lender's stake in the project, and hence leverage, must be increased. For $\lambda>\hat{\lambda}^{\text {max }}$ the first best can no longer be achieved. We summarize as follows:

Proposition 4 There is a threshold $\hat{\lambda}^{\max } \in(0,1)$ such that for any $\lambda \leq \hat{\lambda}^{\text {max }}$ the first best can be achieved once a market for credit protection is introduced. For $\lambda>\hat{\lambda}^{\max }$, the first best cannot be achieved. As $\lambda$ approaches one, the introduction of a credit protection market will have negative implications for credit market efficiency (Proposition 3).

Proof: Follows from the preceding discussion.

Taking excessive protection is "risky" for the lender when renegotiation is imperfect. If a workout is not feasible and the lender's level of protection is above the threshold where he just willing to continue under the original loan contract, the project will be terminated in both states. This is anticipated by the protection seller who consequently charges a very high premium. Keeping protection at the threshold level where he just willing to continue effectively allows the lender to commit to not terminate the project in the good state, given efficient effort. This results in a more affordable premium.

For later reference, notice that a decrease in the asset liquidation value or an increase in the reputational cost of default (i.e., B) relaxes the no-hold-up constraint (6). A decrease in the probability of debt renegotiation being feasible also widens the range of parameter values for which (6) holds. This suggests that firms with relatively low levels of asset tangibility and firms where debt renegotiation is more cumbersome should be more prone to benefit from CDS protection. It also suggests that CDS protection might be more beneficial in economies where default is associated with higher stigma costs for borrowers. As discussed earlier, the effects of the other exogenous parameters of the model, such as $\theta$ and $\Pi$, are ambiguous. Given our quadratic effort cost function, however, it is straightforward to show that $\hat{\lambda}^{\text {max }}$ is increasing in both $\theta$ and $\Pi$ if and only if $B<L / 2$. This may suggest that more profitable ( $\Pi$ high) and safer firms ( $\theta$ high) are more likely to benefit (suffer) from CDS protection when stigma costs associated with default are relatively low (high) or asset liquidation values are relatively high (low). This result, however, may rely on the specific 
functional form for the effort cost function and it may be difficult to draw robust conclusions. The model's empirical implications will be discussed in more detail in Section 5.

\section{Policy Responses}

This section provides a discussion of extensions and policy implications. More specifically, we explore how regulatory limits to CDS protection (Section 4.1), disclosure requirements (Section 4.2), and transaction costs (Section 4.3) may improve equilibrium outcomes.

\subsection{Protection Limits}

A number of recent policy proposals aim at limiting the scope to take negative economic exposures through CDS protection. In the European Union, for example, uncovered ("naked") sovereign CDS - where an investor purchases CDS without holding a position in the underlying sovereign debt-have been prohibited recently. Against this background, the aim of this section is to explore how regulatory limits to CDS protection would perform in our setting. Suppose our lender were, by law, restricted to purchasing protection $C \leq(I-L) / \theta$. If so the hold up problem of excessive protection would not arise and the first best would be achieved. The lender would take the desired level of protection $C=(I-L) / \theta$. Knowing this, the borrower would exert efficient effort. This shows that regulation that imposes limits to protection may have its merits. Of course, the problem with the proposed policy is that it is borrower-specific: it depends on parameters that are unlikely to be observable to regulators, and even if they were it presumably would be prohibitively costly to regulate credit protection transactions on a deal-by-deal basis. The question is how workable regulatory limits to protection would look like in practice.

To shed light on this question, let us first show how the credit protection vehicle considered above can be implemented with a basket of plain vanilla CDS. Suppose the lender advances funds $T \geq I$ against a debt claim with principal and interest of $R_{s}=$ $(T-(1-\theta) L) /\left(\theta e^{F B}\right)$. Let us think of this as the lender purchasing $T$ par bonds, each with a face value of one dollar and a coupon rate of $R_{s} / T-1$. A plain vanilla CDS with a notional value of, say, one dollar specifies that in the event of a default at date 1 the lender is entitled to receive the face value (i.e., \$1) against delivering the default value of the un- 
derlying $\$ 1$ coupon bond. As the default value of the bond is $L / T$ (assuming liquidation proceeds are shared on a pro-rata basis), the lender would have to deliver $L / T$ per CDS to the protection seller. In practice, payment obligations are typically netted, ${ }^{21}$ so that the net payment from the protection seller to the lender is $1-L / T$ per CDS. The credit protection vehicle considered above can then be implemented with a basket of such plain vanilla CDS. To obtain a default-contingent payoff $L+C$, the lender will have to purchase $N$ plain vanilla CDS such that

$$
N(1-L / T)+L=L+C
$$

and therefore $N=C /(1-L / T)$. As $N$ is not restricted by the number of physical one dollar bonds (i.e., $T$ ), the lender can take any level of protection by varying $N$. For example, to achieve the (given $T$ ) socially optimal level of protection, $C=(T-L) / \theta$, the lender will have to purchase $N=T / \theta$ plain vanilla CDS with a notional value of one dollar each. The notional value of the CDS basket is then given by $T / \theta$. This exceeds the lender's investment $T$ (i.e., the face value of the loan) by a factor $1 / \theta>1$. Hence the following

Observation 3 If loss given default ( $L G D)$ is measured relative to the face value of a par loan, the lender will be "overinsured" under the socially optimal level of protection in the sense that the default-contingent payment from the protection seller will exceed LGD.

In other words, a regulatory policy whereby default-contingent protection payouts must not exceed lenders' actual LGD measured relative to the amount invested, i.e., $C \leq T-L$, is suboptimal: under such a policy lenders would be economically underinsured relative to the socially optimal level of protection. The reason why default-contingent payouts must exceed LGD is simple: for the disciplining effect of credit protection to materialize, the lender must be kept indifferent between giving up the continuation value of the loan (given efficient effort) and inducing default in states where the borrower is not economically distressed, i.e., continuation is efficient. This would be the good state in our framework. In the good state, however, the continuation value of the loan necessarily exceeds its face value (as long as $\theta<1)$. Therefore, the economically relevant loss given default, $e^{F B} R_{s}-L$, exceeds loss given default measured relative to face value, $T-L .^{22}$

\footnotetext{
${ }^{21}$ See Bliss and Kaufmann (2006) for an analysis of netting from a systemic risk perspective.

${ }^{22}$ In a recent paper, Campello and Matta (2012) also find that banning CDS "overinsurance" can be suboptimal.
} 
Of course, one may measure LGD not relative to the face value of a par loan (i.e., the amount invested) but relative to amount due, that is, principal and interest. For example, suppose the borrower issued a zero coupon bond. In this case, the face value of the bond would equal principal and interest of an equivalent par bond. Consider a regulatory policy whereby protection payouts are limited to LGD measured relative to amount due. In other words, $C \leq R_{s}-L$. Clearly, as the socially optimal level of protection is $C=e^{F B} R_{s}-L$, such a policy would be not stringent enough.

Observation 4 If $L G D$ is measured relative to amount due, a regulatory policy whereby default-contingent protection payouts must not exceed LGD would allow lenders to take too much protection relative to the socially optimal level of protection.

While protection limits based on LGD measured relative to amount due are not stringent enough, it is still instructive to inquire how such policies would perform. Suppose the lender is restricted to $C \leq R_{s}-L$. From the preceding analysis, we know that the lender would purchase protection $C=e^{F B} \Pi-L$ if he had an incentive to take excessive protection and if he did not face any constraints. Now he faces a constraint and hence $C=\min \left[R_{s}, e^{F B} \Pi\right]-L$. Substituting for the highest incentive-compatible repayment (see Section 3.2.2), $R_{s}^{\max }$, we conclude that the regulatory constraint will be welfare-improving if and only if $R_{s}^{\max }<$ $e^{F B} \Pi .^{23}$ Whether this holds or not depends on the parameters. At any rate, a policy whereby protection payouts are limited LGD measured relative to amount due is weakly welfare-improving and, crucially, it is easy to implement.

Ideally, the protection limit should take the form $C \leq e^{F B} R_{s}-L=(T-L) / \theta$. However, as mentioned earlier, such a policy would rely on parameters that are borrower-specific (viz., $\theta$ ) and unlikely to be observable to regulators. Still, one could contemplate to introduce an ad hoc policy $C \leq \phi R_{s}-L$, where $\phi \in\left(T / R_{s}, 1\right)$ is an ad hoc parameter set by the regulator. This would be either too stringent or not stringent enough in some situations, but it might work in other situations. The overall conclusion is that while welfare-optimizing regulatory protection limits are difficult to implement in practice, there are simple policies that may

\footnotetext{
${ }^{23}$ However, this conclusion is not robust to altering the distribution of bargaining power in renegotiation. If the lender had the full bargaining power he would be able to extract $R_{s}^{\prime}=\Pi$ for any $C>e^{F B} R_{s}-L$. In this case, any regulatory policy with $C \leq e^{F B} R_{s}-L+\epsilon$, where $\epsilon>0$, would be pointless.
} 
improve welfare. At any rate, policies under which protection payouts are limited to LGD measured relative to face value seem too restrictive.

One should also point out that protection limits may have negative implications for CDS market liquidity. A key difference between CDS and credit insurance contracts is that the beneficiary of credit insurance must prove loss. By contrast, the holder a CDS does not have to prove loss. It is precisely this feature that makes CDS tradable. This suggests that CDS market liquidity (and, consequently, price discovery) may suffer when protection payouts are linked to LGD incurred. We will come back to this point in the concluding section.

\subsection{Transparency}

In the wake of the recent financial crisis, policymakers and market participants put forward a number of proposals how transparency in OTC derivatives markets could be increased. These proposals include using central trading (or clearing) platforms, ${ }^{24}$ mandating CDS trade disclosures, or, relatedly, using data repositories that would record details of trades. CDS market transparency may improve contractibility of credit protection and as such improve efficiency in our context. The aim of this section is to show that observability of CDS trades to borrowers can be beneficial in our setting, even when CDS transactions remain non-contractible (e.g., due to limits to complete contracting). The key assumption we make is that the lender must complete any CDS transactions before the borrower exerts effort. To motivate this assumption, notice that once the borrower made her effort choice the lender may have an informational advantage relative to protection sellers. Adverse selection concerns may then prevent the lender from engaging in further profitable CDS trades.

Proposition 5 Suppose the lender's CDS transactions are observable to the borrower before she makes her effort choice. Then, for any $\lambda \in[0,1]$, the first best can be achieved. The optimal financial contract involves the lender advancing funds $T=\theta e^{F B} R_{s}^{\max }+(1-\theta) L>I$ against a short-term debt claim $R_{s}^{\max }=\Pi-\left(\psi\left(e^{F B}\right)-\theta B\right) /\left(\theta e^{F B}\right)$.

Proof: Follows readily from the preceding analysis, and hence omitted.

When CDS trades are observable to the borrower, she can threaten to exert no effort should the lender take excessive protection $C>e^{F B} R_{s}^{\max }-L$. Under the optimal financial

\footnotetext{
${ }^{24}$ For a discussion and further references, see Duffie and Zhu (2011).
} 
contract stated in the proposition, this threat is credible. This is because under the proposed financial structure leverage is at its highest incentive-compatible level (see Section 3.2.2). Therefore, if the lender purchased excessive protection in an attempt to extract additional surplus, the borrower would no longer find it worthwhile to exert positive effort. Taking protection $C=e^{F B} R_{s}^{\max }-L$ is then a strictly dominant strategy for the lender.

There are two caveats. The first caveat is that the proposition relies on the assumption that the lender cannot take additional protection once the borrower's effort cost is sunk. The second caveat is that the equilibrium is not "perturbation-proof" in the sense that small unanticipated shocks to the model parameters may have a profound impact on outcomes. For example, an unanticipated very small negative shock to the project return $\Pi$ just before the borrower makes her effort choice would result in zero effort. ${ }^{25}$ To obtain a less fragile financial structure the parties may choose less than maximum leverage, $R_{s}<R_{s}^{\max }$. Such a policy would not achieve the first best but it would be more robust. In any case, disclosures of CDS transactions can have their merits in our setting-because they either facilitate contractibility or force lenders to internalize the costs of taking excessive protection.

\subsection{Transaction Costs}

One could also contemplate to "tax" lenders' transactions in the CDS market in order to limit their incentive to take excessive protection. This could be achieved directly by introducing a tax schedule or indirectly, e.g., through a capital adequacy regulation scheme under which lenders would have to set aside capital when purchasing CDS. ${ }^{26}$ Lenders may also face transaction costs in the CDS market, e.g., in the form of illiquidity or adverse selection premia. Thus, CDS protection could be subject to transaction or opportunity costs, which may limit lenders' incentive to take excessive protection. We will illustrate below that an appropriately designed cost schedule may indeed work. However, the discussion will also show that such a cost schedule might be complex and difficult to implement in practice.

\footnotetext{
${ }^{25}$ This is because under the proposed financial structure the borrower is indifferent between exerting efficient effort and exerting zero effort (conditional on $C=e^{F B} R_{s}^{\max }-L$ ). As a result, a small unanticipated decrease in $\Pi$ just before the borrower makes her effort choice would result in zero effort.

${ }^{26}$ It is worth emphasizing that under such a scheme CDS protection would not give rise to capital relief- to the contrary, lenders would be forced to set aside more capital when purchasing protection.
} 
To fix ideas, suppose the lender faces total transaction costs $c \times C^{2}$ when purchasing protection $C$, where $c>0$. By inspection, the cost schedule is increasing and convex in $C$. As above, credit protection is non-contractible and non-observable to the borrower when taking her effort decision. Let us show under which conditions efficient effort can be induced even if there are no obstacles to renegotiation. An immediate observation is that in an equilibrium in which the borrower exerts efficient effort the parties must renegotiate in equilibrium. To see this, notice that if there were no workout in equilibrium, i.e., the project were continued without renegotiation in the good state, then the lender's best response would be to purchase no protection (given that he faces the cost). Yet, if the lender does not purchase protection, the borrower's best response is to exert less than efficient effort. ${ }^{27}$ The second observation is that given that there will be a workout in equilibrium, the lender's payoff in the good state is purely determined by his outside option payoff, $L+C$.

Suppose the lender purchases some level of protection $C^{*} \leq e^{F B} \Pi-L$. What is the borrower's best response? The borrower knows that if she exerts effort $e$ she will have to commit to pay $R^{\prime}=\left(L+C^{*}\right) / e$ to induce the lender to continue in the good state. Thus efficient effort is locally incentive-compatible. ${ }^{28}$ Global incentive-compatibility requires that the borrower prefers efficient effort to zero effort,

$$
\theta e^{F B}\left(\Pi-\left(L+C^{*}\right) / e^{F B}\right)-(1-\theta) B-\psi\left(e^{F B}\right) \geq-B
$$

This can be rewritten as

$$
C^{*} \leq e^{F B} \Pi-L-\left(\psi\left(e^{F B}\right) / \theta-B\right)
$$

The lender purchases protection as to

$$
\max _{C} L+\theta C-c C^{2}
$$

This is solved for $C^{*}=\theta /(2 c)$. Substituting for $C^{*}$, the borrower's incentive constraint (7) reduces to

$$
c \geq \frac{\theta}{2\left(e^{F B} \Pi-L-\left(\psi\left(e^{F B}\right) / \theta-B\right)\right)}>0
$$

\footnotetext{
${ }^{27}$ Conditional on no workout occurring in equilibrium, the borrower's best response to $C=0$ is efficient effort if and only if $R_{s}=0$. This, however, would violate the lender's participation constraint (given that there is no workout in equilibrium that would allow the lender to extract a payment from the borrower). ${ }^{28}$ That is, $\theta e\left(\Pi-R^{\prime}\right)-(1-\theta) B-\psi(e)$ is maximized at $e^{F B}$.
} 
We next need to check whether investment is feasible. The lender's zero profit constraint is

$$
L+\theta C^{*}-c\left(C^{*}\right)^{2}-T=L+\theta /(4 c)-T=0
$$

where $T$ is the initial transfer. Investment is feasible if and only if $T \geq I$, i.e.,

$$
c \leq \frac{\theta}{4(I-L)}
$$

In summary, if (8) and (9) both hold, i.e., the marginal cost $c$ is neither too small nor too large, efficient effort can be implemented once a market for credit protection is introduced.

Proposition 6 Suppose the lender faces total transaction costs $c \times C^{2}$ when taking protection $C$ and there are no obstacles to renegotiation. Then, efficient effort can be implemented in equilibrium provided the marginal transaction cost $c$ is neither too small nor too large.

Proof: Follows from the preceding discussion.

Two observations are in order. First, the cost schedule must be convex. If the cost schedule were not convex the lender would either purchase excessive protection (assuming no obstacles to renegotiation) or no protection at all: a linear cost schedule would be pointless. Yet, a convex cost schedule is difficult to implement. The difficulty is that protection cannot be taxed on a transaction by transaction basis - otherwise lenders would divide larger transactions into smaller ones in order to minimize the "tax" burden (thereby effectively "linearizing" the tax exposure). Taxes on incremental purchases of protection would have to depend on the level of protection that a lender already has in place. The second observation is that the optimal tax schedule is deal-specific: the marginal tax must be neither too small nor too large relative to thresholds that depend on the borrower in question. Such borrower-specific tax schedules are clearly infeasible in practice.

\section{Empirical Implications}

As seen earlier, firms with relatively low levels of asset tangibility and firms where debt renegotiation is more difficult are more likely to benefit from the development of CDS markets. To the extent that debt renegotiation is more difficult at large firms-i.e., firms that often have relatively complex and dispersed financial structures - this suggests that the 
benefits of CDS protection may be confined to relatively large firms. Furthermore, as firms with low levels of asset tangibility tend to have low leverage, ${ }^{29}$ the model predicts that firms with relatively low leverage ex ante should be more prone to benefit from the introduction of CDS. Following the introduction of CDS markets, these firms should experience improved credit availability, increased firm value, and lower risk of default. The effect on interest rates (or spreads) is less clear-cut, though. As seen earlier, leverage may increase following the introduction of CDS. This will tend to increase spreads. At the same time, default risk (probability of default) decreases, which will tend to lower spreads. ${ }^{30}$ The effect on spreads is therefore ambiguous, at least if changes in leverage are not controlled for. ${ }^{31}$ We summarize the first set of predictions as follows:

Implication 1 Firms with low asset tangibility, firms with low leverage ex ante, and large firms should be more prone to benefit from the development of CDS markets. These firms should experience improved credit supply, an increase in firm value, and a decrease in default risk. Leverage should on average increase, and hence spreads could decrease or increase.

Some of these predictions have been tested. Ashcraft and Santos (2009) examine the impact of CDS trading on spreads that the underlying firms pay to raise funding in the corporate bond and syndicated loan markets in the US. Hirtle (2009) investigates the effect of credit derivatives usage on bank credit supply and loan spreads in the US. While both papers find that CDS trading or usage has little effect on the average borrower, Ashcroft and Santos (2009) find that firms with low leverage experience a decrease in spreads at the onset of CDS trading, and Hirtle (2009) finds that new loans to large borrowers tend to increase as banks take on more credit protection (but spreads increase too). Both findings seem to be consistent with our model. Ashcroft and Santos (2009) moreover find that informationally more transparent firms and firms with lower stock volatility are more prone to benefit from CDS. Shim and Zhu (2010), in a study of the impact of CDS trading on spreads in Asian bond markets, instead find that more opaque firms tend to benefit more. They also find

\footnotetext{
${ }^{29}$ For recent evidence, see Campello and Giambona (2012).

${ }^{30}$ Formally, in our model, spreads are given by $\left(T-(1-\theta) L /\left(\theta e^{*} T\right)-1\right.$, where $T \geq I$ (with strict inequality for some borrowers) and $e^{*}$ is equilibrium effort. This is increasing in $T$ and decreasing in $e^{*}$.

${ }^{31}$ Another reason why spreads could increase is that improved credit availability may enable firms to engage in new and risky activities. Overall default risk at the firm level may thus increase.
} 
that firms with high leverage and smaller firms are more prone to benefit - in contrast to what Ashcroft and Santos (2009) find for the US and somewhat opposite to what our model would predict. In summary, the empirical evidence on the impact of CDS usage on spreads is mixed and it may be difficult to draw general conclusions.

The second set of implications concerns firms that would be made worse off by the introduction of CDS markets. As these firms would suffer from the excessive rent extraction problem, they should become more reluctant to agree to debt maturity designs and control right transfers that would enable their lenders to impose foreclosure (and hence hold up) threats in the first place. Following the introduction of CDS markets, one would thus expect a lengthening of debt maturities and a shift towards relatively more covenant-lite debt. In the context our model, such a shift to covenant-lite long-term debt should be observed regardless of whether a firm's lender actually uses CDS. All what matters in our model is that a lender could purchase CDS on a firm's debt if he wanted to. As a result, the mere introduction of CDS could have negative effects on firms even if lenders actually do not purchase CDS on these firms' debt. It should be stressed, however, that this is somewhat an artifact of our model and due to the simplifying assumption that lenders' sole motivation to take protection is to enhance the value of their exit options. In practice, there will be many other reasons, and hence it seems plausible that lenders will purchase protection when they have the opportunity to do so. In any case, we have the following implication.

Implication 2 Following the introduction of CDS markets, one should observe a lengthening of debt maturities and a shift to relatively more covenant-lite debt.

The first prediction (lengthening of debt maturities) seems to be consistent with the empirical evidence reported in Saretto and Tookes (2012). They find that firms with traded CDS contracts on their debt maintain longer debt maturities (and also higher leverage ratios). They also find that these effects are more pronounced during periods in which credit constraints become binding. As explained by Saretto and Tookes (2012), this is consistent with the notion that lenders' improved ability to hedge alleviates frictions on the supply side of markets. Another explanation is offered by our model: firms that would suffer from the rent extraction problem shift away from financial contract designs that would enable their lenders to impose hold up threats. To our knowledge, the second prediction 
(more covenant-lite debt) has not been tested yet.

The analysis also has implications for financial stability. CDS protection can enhance credit market efficiency and support the extension of credit. This, however, does not necessarily imply that CDS protection, even when improving credit availability, has positive implications for financial stability. To the extent that CDS protection reduces credit constraints, it might be the least creditworthy and presumably riskiest borrowers that benefit most from the relaxation of credit constraints. At the same time, default probabilities of borrowers that previously were not credit rationed might decrease due to the disciplining effect of protection. The overall effect on financial stability and default risk in the economy is then ambiguous. Furthermore, an increase in overall default risk following the introduction of CDS markets does not necessarily imply that CDS protection is detrimental to welfare. ${ }^{32}$ However, the analysis also suggests that CDS protection could at times be highly detrimental to financial stability and welfare. While the framework proposed in this paper is too simplistic to draw robust system risk implications, one result is that, in extreme cases, CDS markets could have severe ripple effects on the viability of credit markets.

\section{Concluding Remarks}

We proposed a simple model to analyze the effects of CDS protection on corporate lending and credit market efficiency. CDS insulate lenders against losses from letting borrowers default. This strengthens the credibility of termination threats vis-⿳亠㐅⿵--vis borrowers, which in turn affects borrower incentives and credit constraints ex ante. Provided lenders' protection levels are sufficiently limited, this effect goes in the direction of relaxing incentive and credit constraints. The introduction of a market for credit protection will then have positive implications for the extension of credit and overall credit market efficiency.

However, to the extent that lenders' protection levels are unobservable and difficult to contract upon, lenders may have an incentive to take excessive protection in an attempt to hold up borrowers and extract additional surplus in debt renegotiations. If this threat becomes sufficiently severe, borrower incentives will be severely stifled. The parties will

\footnotetext{
${ }^{32}$ See Keys, Mukherjee, and Seru (2010) for an empirical design that accounts for this issue in the context of securitization.
} 
have to resort to inefficient covenant-lite types of financing under which lenders are not entitled to force pre-mature liquidation. This may lead to a situation where borrowers that would have obtained funding in the absence of credit protection will find themselves credit rationed once credit protection is introduced.

Lenders' incentive to take excessive protection will be limited when debt renegotiation is subject to obstacles that may render private workouts infeasible. Protection sellers are willing to advance protection against relatively low premia only if they can be ensured that termination threats are not exercised in states where continuation is efficient. This requires that lenders and borrowers are able to sort out matters in workouts. As a result, ex ante uncertainty about the feasibility of workouts may make taking excessive protection prohibitively costly for lenders as it would entail excessively high premia. To the extent that renegotiation is more cumbersome at large and complex organizations, this suggests that large firms may be more prone to benefit from the introduction of a market for credit protection. We also provided a discussion of policy options, and concluded that regulatory measures aimed at limiting the scope to take excessive protection may be difficult to implement in practice and may have undesirable "unintended consequences".

Understanding the costs and benefit of CDS market liquidity (or illiquidity) from a corporate finance and debt contracting perspective is an interesting avenue for future research. ${ }^{33}$ One immediate implication of our model is that "small" borrowers, i.e., borrowers for which the CDS market is currently highly illiquid if not non-existent (cf., Minton, Stulz, and Williamson 2009), may actually benefit from CDS market illiquidity - to the extent that these are precisely the types of borrowers that would suffer most from the excessive rent extraction problem of CDS protection highlighted above.

\section{References}

Allen, F., and E. Carletti, 2006, "Credit Risk Transfer and Contagion," Journal of Monetary Economics, 53, 89-111.

Arping, S., 2004, "Credit Protection and Lending Relationships," Working Paper, University of Amsterdam.

\footnotetext{
${ }^{33}$ For an empirical analysis of the informational role of CDS prices for bank lending and loan pricing, see Norden and Wagner (2008).
} 
Ashcraft, A. and J. Santos, 2009, "Has the CDS Market Lowered the Cost of Corporate Debt?" Journal of Monetary Economics, 56, 514-523.

Berglöf, E. and E. von Thadden, 1994, "Short-Term versus Long-Term Interests: Capital Structure with Multiple Investors," Quarterly Journal of Economics, 109, 1055-1084.

Bliss, R. and G. Kaufmann, 2006, "Derivatives and Systemic Risk: Netting, Collateral, and Closeout," Journal of Financial Stability, 2, 55-70.

Bolton, P. and M. Oehmke, 2011, "Credit Default Swaps and the Empty Creditor Problem," Review of Financial Studies, 24, 2617-2655.

Bolton, P. and D. Scharfstein, 1996, "Optimal Debt Structure and the Number of Creditors," Journal of Political Economy, 104, 1-25.

Carlstrom, C. and K. Samolyk, 1995, "Loan Sales as a Response to Market-Based Capital Constraints," Journal of Banking and Finance, 19, 627-646.

Campello, M. and E. Giambona, 2012, "Real Assets and Capital Structure," Working Paper, Cornell University and University of Amsterdam.

Campello, M. and R. Matta, 2012, "Credit Default Swaps, Firm Financing and the Economy," Working Paper, Cornell University.

Che, Y. and R. Sethi, 2010, "Credit Derivatives and the Cost of Capital," Working Paper, Columbia University.

Chiesa, G., 2008, "Optimal Credit Risk Transfer, Monitored Finance, and Banks," Journal of Financial Intermediation, 17, 464-477.

Dewatripont, M. and J. Tirole, 1994, "A Theory of Debt and Equity: Diversity of Securities and Manager-Shareholder Congruence," Quarterly Journal of Economics, 109, 1027-1054.

Duffee, G. and C. Zhou, 2001, "Credit Derivatives in Banking: Useful Tools for Managing Risk?" Journal of Monetary Economics, 48, 25-54.

Duffie, D., and H. Zhu, 2011, "Does a Central Clearing Counterparty Reduce Counterparty Risk?," Working Paper, Stanford University.

Fostel, A. and J. Geanakoplos, 2011, "Tranching, CDS, and Asset Prices: How Financial Innova- 
tion Can Cause Bubbles and Crashes," Working Paper, Yale University.

Geanakoplos, J., 2009, "The Leverage Cycle," Working Paper, Yale University.

Goderis, B. and W. Wagner, 2005, "Credit Derivatives and Sovereign Debt Crises," Working Paper, Tilburg University.

Gorton, G. and G. Pennacchi, 1995, "Banks and Loan Sales: Marketing Nonmarketable Assets," Journal of Monetary Economics, 35, 389-411.

Hirtle, B., 2009, "Credit Derivatives and Bank Credit Supply," Journal of Financial Intermediation, 18, 125-150.

Hu, H. and B. Black, 2008, "Debt, Equity, and Hybrid Decoupling: Governance and Systemic Risk Implications," European Financial Management, 14, 663-709.

Jostarndt, P. and Z. Sautner, 2010, "Out-of-Court Restructuring versus Formal Bankruptcy in a Non-Interventionist Bankruptcy Setting," Review of Finance, 14, 623-668.

Keys, B., Mukherjee, T., Seru, A. and V. Vig, 2010, "Did Securitization Lead to Lax Screening? Evidence from Subprime Loans," Quarterly Journal of Economics, 125, 307-362.

Marsh, I. and W. Wagner, 2006, "Credit Risk Transfer and Financial Sector Stability," Journal of Financial Stability, 2, 173-193.

Matta, R., 2011, "Optimal Financing with CDS Markets," Working Paper, University of Illinois.

Minton, B., Stulz, R., and R. Williamson, 2009, "How Much Do Banks Use Credit Derivatives to Hedge Loans?," Journal of Financial Services Research, 35, 1-31.

Morrison, A., 2005, "Credit Derivatives, Disintermediation and Investment Decisions," Journal of Business, 78, 621-648.

Norden, L., and W. Wagner, 2008, "Credit Derivatives and Loan Pricing," Journal of Banking and Finance, 32, 2560-2569.

Opler, T. and S. Titman, 1994, "Financial Distress and Corporate Performance," Journal of Finance, 49, 1015-1040.

Parlour, C. and G. Plantin, 2008, "Loan Sales and Relationship Banking," Journal of Finance, 63, 1291-1314. 
Pennacchi, G., 1988, "Loan Sales and the Cost of Bank Capital," Journal of Finance, 43, 375-396.

Rajan, R., 1992, "Insiders and Outsiders: The Choice Between Informed and Arm's Length Debt," Journal of Finance, 47, 1367-1400.

Repullo, R. and J. Suarez, 1998, "Monitoring, Liquidation, and Security Design," Review of Financial Studies, 11, 163-187.

Sambalaibat, B., 2011, "Credit Default Swaps and Sovereign Debt with Moral Hazard and Debt Renegotiation," Working Paper, Carnegie Mellon University.

Saretto, A. and H. Tookes, 2012, "Corporate Leverage, Debt Maturity and Credit Supply: The Role of Credit Default Swaps," Working Paper, University of Texas at Dallas.

Scott-Quinn, B. and J. Walmsley, 1998, "The Impact of Credit Derivatives on Securities Markets," Manuscript, International Securities Market Association, Zurich.

Shim, I. and H. Zhu, 2010, "The Impact of CDS Trading on the Bond Market: Evidence from Asia," Working Paper, Bank for International Settlements.

Stulz, R., 2010, "Credit Default Swaps and the Credit Crisis," Journal of Economic Perspectives, $24,73-92$.

\section{Appendix: Proofs}

\section{Proof of Proposition 1}

Consider the case of short-term debt. If undertaken, the project must be continued in the good state. Furthermore, restricting without loss of generality attention to contracts that are renegotiation-proof in equilibrium, the project must be continued without renegotiation in equilibrium (in the good state). Thus an optimal contract solves

$$
\begin{aligned}
\max _{\left(e^{*}, R_{s}\right)} & \theta e^{*}\left(\Pi-R_{s}\right)-(1-\theta) B-\psi\left(e^{*}\right) \\
\text { s.t. } & \\
& e^{*} R_{s} \geq L \\
& \theta e^{*} R_{s}+(1-\theta) L \geq I \\
& e^{*} \text { is incentive-compatible }
\end{aligned}
$$

where $e^{*}$ is the candidate equilibrium effort level, $(\mathrm{CO})$ ensures that the lender has an appropriate incentive to continue the project in the good state, conditional on $e^{*}$, (IR) is the lender's participation constraint, and (IC), which is yet to be derived, is the borrower's incentive constraint. At the optimum, (IR) holds 
with equality. Substituting for $R_{s}=(I-(1-\theta) L) /\left(\theta e^{*}\right)$, (CO) reduces to $I \geq L$, which holds with strict inequality by $I>L$. Let us now derive (IC). Suppose the borrower exerts effort $e$, possibly different from $e^{*}$ and consider the continuation game in the good state (in the bad state the project will be terminated). For $e \geq L / R_{s}$, the lender prefers to continue and, moreover, continuation is efficient. Hence the project will be continued without renegotiation. For $e<L / R_{s}$, the lender prefers to terminate under the status-quo contract. If renegotiation is not feasible (probability $1-\lambda$ ), he terminates the project. If renegotiation is feasible (probability $\lambda$ ), and termination is inefficient, the borrower offers the lender a new claim $R_{s}^{\prime}>R_{s}$ such that lender is just willing to continue, $e R_{s}^{\prime}=L$. As the borrower cannot pledge more than $\Pi$, renegotiation will succeed if and only if $e \geq L / \Pi$. For $e \in[(L-B) / \Pi, L / \Pi)$, continuation is still efficient, but the borrower cannot give the lender a large enough claim to induce him to continue. In summary, the borrower's payoff from exerting effort $e$ is

$$
U(e)= \begin{cases}\theta e\left(\Pi-R_{s}\right)-(1-\theta) B-\psi(e) & \text { for } e \geq L / R_{s} \\ \lambda(\theta(e \Pi-L)-(1-\theta) B)-(1-\lambda) B-\psi(e) & \text { for } e \in\left[L / \Pi, L / R_{s}\right) \\ -B-\psi(e) & \text { for } e<L / \Pi\end{cases}
$$

Notice that $L / R_{s}<e^{*}$ by $L<I$. Thus, $e^{*}$ is locally incentive compatible if and only if

$$
U^{\prime}\left(e^{*}\right)_{e \geq L / R_{s}}=\theta\left(\Pi-\frac{I-(1-\theta) L}{\theta e^{*}}\right)-2 \beta e^{*}=0
$$

where we substituted for $\psi^{\prime}\left(e^{*}\right)=2 \beta e^{*}$. Global incentive-compatibility requires $U\left(e^{*}\right) \geq U(e)$ for all $e$. Yet,

$$
\max _{e} U(e)_{e \in\left[L / \Pi, L / R_{s}\right)} \leq \max _{e} U(e)_{e \in\left[L / \Pi, L / R_{s}\right)} \mid \lambda=1<U\left(L / R_{s}\right)_{e \geq L / R_{s}}<U\left(e^{*}\right)_{e \geq L / R_{s}}
$$

and

$$
U\left(e^{*}\right)_{e \geq L / R_{s}}=\underbrace{\theta e^{*} \Pi+(1-\theta)(L-B)-\psi\left(e^{*}\right)-I}_{\text {project NPV }} \geq 0>\max _{e} U(e)_{e<L / \Pi}=-B
$$

since if NPV had been negative the project would not have been undertaken in the first place. In summary, (IC) boils down to (IC'). The problem reduces to

$$
\max _{e^{*}} \theta e^{*} \Pi+(1-\theta)(L-B)-\psi\left(e^{*}\right)-I
$$

subject to (IC'). (IC') is a quadratic equation which has at most two solutions. Since any such solution is less than $e^{F B}$, equilibrium effort will be given by the largest solution of (IC'). This is solved for

$$
e_{s}^{*}=\frac{\theta \Pi+\sqrt{(\theta \Pi)^{2}-8 \beta(I-(1-\theta) L)}}{4 \beta}<e^{F B}
$$

as stated in the proposition.

We next derive the debt capacity threshold. In equilibrium the project will be undertaken if and only if (i) $e_{s}^{*}$ is a real number, i.e., the term inside the square root is non-negative,

$$
I \leq(\theta \Pi)^{2} /(8 \beta)+(1-\theta) L \equiv I_{s}^{\prime}
$$

and (ii) project NPV is non-negative. It is straightforward to show that at $e_{s}^{*}\left(I_{s}^{\prime}\right)=\theta \Pi /(4 \beta), \mathrm{NPV}$ is non-negative if and only if

$$
I \leq 3(\theta \Pi)^{2} /(16 \beta)+(1-\theta)(L-B) \equiv I_{s}^{\prime \prime}
$$

Let then $I_{s}=\min \left[I_{s}^{\prime}, I_{s}^{\prime \prime}\right]$ and notice that $I_{s}<\theta e^{F B} \Pi+(1-\theta)(L-B)-\psi\left(e^{F B}\right)=(\theta \Pi)^{2} /(4 \beta)+(1-\theta)(L-B)$ by $I_{s}^{\prime \prime}<(\theta \Pi)^{2} /(4 \beta)+(1-\theta)(L-B)$. In conclusion, there is a threshold $I_{s}<\theta e^{F B} \Pi+(1-\theta)(L-B)-\psi\left(e^{F B}\right)$ such that the project is undertaken in equilibrium if and only if $I \leq I_{s}$. The proof that $e_{l}^{*}<e_{s}^{*}$ and $I_{l}<I_{s}$ is straightforward and hence omitted. 


\section{Proof of Proposition 2}

Let the lender advance funds $I$ against a claim $R_{s}=(I-(1-\theta) L) /\left(\theta e^{F B}\right)$. Furthermore, let the lender purchase credit protection $C=(I-L) / \theta$ against a premium $P=(1-\theta) C$. Under this contract, the lender is willing to continue in the good state if and only if $e \geq e^{F B}$. In the bad state, he terminates. Moreover, if the borrower exerts efficient effort and the project is continued (terminated) in the good (bad) state, investors just break even. It remains to be shown that the borrower's incentive constraint is slack. Going through the same steps as in the proof of Proposition 1, it is straightforward to show that the borrower's payoff from exerting effort $e$ is

$$
U(e)= \begin{cases}\theta e\left(\Pi-R_{s}\right)-(1-\theta) B-\psi(e) & \text { for } e \geq e^{F B} \\ \lambda(\theta(e \Pi-(L+C))-(1-\theta) B)-(1-\lambda) B-\psi(e) & \text { for } e \in\left[(L+C) / \Pi, e^{F B}\right) \\ -B-\psi(e) & \text { for } e<(L+C) / \Pi\end{cases}
$$

To show that $e^{F B}$ is incentive-compatible, notice

$$
\max _{e} U(e)_{e \in\left[(L+C) / \Pi, e^{F B}\right)} \leq \max _{e} U(e)_{e \in\left[(L+C) / \Pi, e^{F B}\right)} \mid \lambda=1<\max _{e} U(e)_{e \geq e^{F B}}=U\left(e^{F B}\right)_{e \geq e^{F B}}
$$

and

$$
U\left(e^{F B}\right)_{e \geq e^{F B}}=\theta e^{F B} \Pi+(1-\theta)(L-B)-\psi\left(e^{F B}\right)-I>0>\max _{e} U(e)_{e<(L+C) / \Pi}=-B
$$

by (1). Hence efficient effort is incentive-compatible.

\section{Proof of Proposition 3}

We have shown in the text that for $B<\psi\left(e^{F B}\right) / \theta$ the first best cannot be achieved. Here, we show that for $B \in\left[\psi\left(e^{\min }\right) / \theta, \psi\left(e^{F B}\right) / \theta\right)$, where $e^{\min }$ is the critical effort level where project NPV is just zero, shortterm debt financing is still feasible, whereas for $B<\psi\left(e^{\mathrm{min}}\right) / \theta$ it is not. Consider a candidate equilibrium in which the project is financed with short-term debt $R_{s}=\Pi$ and the borrower exerts effort $e^{*}$. From the text we know that the lender's best response is to purchase protection $C=e^{*} \Pi-L$. Effort $e^{*}$ is incentive-compatible if and only if

$$
\theta e^{*}\left(\Pi-R_{s}\right)-(1-\theta) B-\psi\left(e^{*}\right)=-(1-\theta) B-\psi\left(e^{*}\right) \geq-B
$$

or $B \geq \psi\left(e^{*}\right) / \theta$. The lender's zero-profit constraint is

$$
\theta e^{*} \Pi+(1-\theta) L=T
$$

where $T$ is the initial transfer. Investment is feasible if and only if $\theta e^{*} \Pi+(1-\theta) L \geq I$. The borrower's payoff, in turn, is

$$
-(1-\theta) B-\psi\left(e^{*}\right)+(T-I)=\theta e^{*} \Pi+(1-\theta)(L-B)-\psi\left(e^{*}\right)-I
$$

which is project NPV. Thus the borrower is willing to participate if and only if project NPV is nonnegative. If so investment is feasible too. Let then $e^{\min }$ denote the critical effort level where NPV is zero. As long as $B \geq \psi\left(e^{\mathrm{min}}\right) / \theta$, effort $e^{\min }$ or higher can be made incentive-compatible, short-term debt financing is feasible, and credit protection may have positive implications for credit market efficiency. For $B<\psi\left(e^{\min }\right) / \theta$, short-term debt financing is not feasible. 